\title{
Tousled-like kinase functions with the chromatin assembly pathway regulating nuclear divisions
}

\author{
Pilar Carrera, ${ }^{1,4}$ Yuri M. Moshkin, ${ }^{2,4}$ Sebastian Grönke, ${ }^{1}$ Herman H.W. Silljé, ${ }^{3}$ Erich A. Nigg, ${ }^{3}$ \\ Herbert Jäckle, ${ }^{1,5}$ and François Karch ${ }^{2,6}$ \\ ${ }^{1}$ Abteilung Molekulare Entwicklungsbiologie, Max-Planck-Institut für biophysikalische Chemie, Am Fassberg, D-37077 \\ Göttingen, Germany; ${ }^{2}$ Department of Zoology and Animal Biology and NCCR Frontiers in Genetics, University of Geneva, \\ CH-1211 Geneva 4, Switzerland; ${ }^{3}$ Max-Planck-Institute for Biochemistry, Am Klopferspitz 18a, D-82152 \\ Martinsried, Germany
}

Tousled-like kinases (TLKs) constitute a family of serine/threonine kinases conserved in plants and animals that act in a cell cycle-dependent manner. In mammals, their activity peaks during $S$ phase, when they phosphorylate the antisilencing function protein 1 (ASF1), a histone chaperone involved in replication-dependent chromatin assembly. Here, we show that Drosophila ASF1 is also a phosphorylation target of TLK, and that the two components cooperate to control chromatin replication in vivo. By altering TLK activity through loss-of-function mutations, we show that nuclear divisions are arrested at interphase, followed by apoptosis. Overexpression of TLK alters the chromatin structure, suggesting that TLK mediates the activity of chromatin proteins. These results suggest that TLK coordinates cell cycle progression through the regulation of chromatin dynamics.

[Keywords: Anti-silencing function protein 1; cell cycle; chromatin structure; histone chaperone; tousled-like kinase]

Received April 14, 2003; revised version accepted August 18, 2003.

DNA of eukaryotes is wrapped repetitively around histone octameres, forming nucleosomal arrays. This socalled beads-on-a-string arrangement constitutes the backbone for building higher-order chromatin structures (Luger et al. 1997). Distinct chromatin structures are assembled depending on covalent histone tail modifications (histone-code), resulting in activation or repression of gene expression. These active/silenced chromatin states are epigenetically inherited through cell divisions (Turner et al. 1992; Jenuwein and Allis 2001; Richards and Elgin 2002). During S phase, nucleosomal array, and consequently, higher-order chromatin complexes, are partially disrupted by the passage of the replication forks (Sogo et al. 1986; Gruss et al. 1993). Therefore, in order to transmit the epigenetic state of chromatin through the cell cycle, nucleosomal arrays must be duplicated faithfully during DNA replication (Enomoto and Berman 1998; Shibahara and Stillman 1999; Zhang et al. 2000).

Assembly of newly synthesized DNA onto nucleosomes is under the control of replication-dependent

\footnotetext{
${ }^{4}$ These two authors contributed equally to this work.

Corresponding authors.

${ }^{5}$ E-MAIL hjaeckl@gwdg,de; FAX 49-551-2011755.

${ }^{6}$ E-MAIL francois.karch@zoo.unige.ch; FAX 41-22-3796439.

Article and publication are at http://www.genesdev.org/cgi/doi/10.1101/ $\operatorname{gad} .276703$.
}

chromatin assembly systems (for review, see Mello and Almouzni 2001; Tyler 2002). It involves the deposition of a histone $\mathrm{H} 3$ and $\mathrm{H} 4$ tetramer onto the newly generated daughter strands, followed by incorporation of two histone $\mathrm{H} 2 \mathrm{~A}-\mathrm{H} 2 \mathrm{~B}$ dimers to complete the nucleosome core particles (Smith and Stillman 1991; Lucchini et al. 2001). This process is facilitated by histone chaperones such as the chromatin assembly factor 1 (CAF-1) and by the recently identified antisilencing function protein 1 (ASF1). Additionally, ATP-dependent chromatin remodeling factors are required to produce regularly spaced arrays (for review, see Mello and Almouzni 2001; Tyler 2002).

Coupling of chromatin assembly and DNA synthesis is, in part, mediated by interactions between CAF- 1 and PCNA, a loading factor for the replication machinery. This association is thought to be important for the location of the chromatin assembly factors to the sites of DNA synthesis (Shibahara and Stillman 1999; Zhang et al. 2000). Further biochemical analysis revealed that CAF-1 nucleosome assembly activity on replicating DNA is facilitated by the replication-coupling assembly factor (RCAF) complex (Tyler et al. 1999, 2001; Mello et al. 2002) composed of ASF1 and newly synthesized acetylated histones H3 and H4 (Tyler et al. 1999). Gene disruption studies of CAF-1 subunits in yeast (Tyler et 
al. 1999) and asf1 in yeast and flies (Sharp et al. 2001; Moshkin et al. 2002; Umehara et al. 2002) support the idea that de novo chromatin assembly is required for epigenetic inheritance of silenced chromatin. In yeast, the lack of ASF1 activity causes a substantial slowing down of the cell cycle in S phase, an effect that is enhanced by mutations in CAF-1 subunits (Le et al. 1997; Tyler et al. 1999). Both genetic and biochemical data suggest that ASF1 functions synergistically with CAF-1 in the regulation of chromatin assembly and cell divisions (Tyler et al. 1999, 2001; Sharp et al. 2001; Mello et al. 2002).

In mammals, ASF1 has been identified as a phosphorylation target of the cell cycle-regulated Tousled-like kinases (TLKs). These kinases are members of a conserved serine/threonine kinase family present in both animals and plants (Silljé and Nigg 2001). The prototype TLK in Arabidopsis thaliana was shown to be essential for proper flower and leaf development by possibly regulating cell divisions (Roe et al. 1993, 1997). Mammalian TLKs are localized in the nucleus during interphase and display maximal activity during $S$ phase, when DNA synthesis and replication-dependent chromatin assembly occur (Silljé et al. 1999). In further studies, TLKs have also been shown to be able to phosphorylate Ser 10 of histone $\mathrm{H} 3$ (Li et al. 2001).

We describe the function of the single tousled-like kinase (tlk) gene of Drosophila. Analysis of tlk mutants shows that reduced $t l k$ levels cause abnormal nuclear divisions followed by apoptotic death, and that increased tlk levels alter the chromatin structure. TLK interacts in vitro with ASF1, resulting in phosphorylation of ASF1. In vivo, TLK cooperates with ASF1 in the control of endoreplication, indicating that TLK regulates cell cycle progression through the chromatin assembly pathway.

\section{Results}

\section{Characterization of the Drosophila tlk}

The Drosophila genome contains only a single member of the Tousled-like kinase family of genes, termed tousled-like kinase (tlk). The gene is located in the region 3F of the Drosophila X chromosome (Adams et al. 2000; Fig. 1A). Comparison of the t1k cDNA sequences (LD15160, GH07910) with the corresponding genomic DNA sequences (Berkeley Drosophila Genome Project, BDGP) revealed that the gene encodes alternatively spliced transcripts. They differ in their $3^{\prime}$ untranslated region, resulting from the use of different polyadenylation sites. In addition, they have an alternatively spliced first exon. The predicted proteins share a common ORF of 1242 residues and differ in the $\mathrm{N}$-terminal region /details in legend to Fig. 1). The structure of the gene, the deduced amino acid sequence of TLK, and a comparison with human and Arabidopsis homologs are summarized in Figure 1.

TLK, human TLK1 and TLK2, and the Tousled kinase of Arabidopsis (TSL) show a high degree of sequence conservation in the $\mathrm{C}$-terminal serine/threonine kinase do- main with $71 \%, 68 \%$, and $52 \%$ sequence similarity, respectively (Fig. 1B). The catalytic domain of TLKs carries an unusual ATP-binding motif, which contains a GXGXXS (position 73-78; Fig. 1B) instead of the canonical GXGXXG motif (Hanks et al. 1988). A structural comparison of Drosophila TLK with mammalian and plant homologs is shown in Figure 1C.

\section{tlk expression patterns and subcellular protein localization}

In situ hybridization of the $t 1 k$ cDNA probe to ovaries shows that the transcripts are expressed in nurse cells from where they are transported into the oocyte (data not shown). $t$ lk transcripts remain ubiquitously distributed in the egg and throughout embryonic development (Fig. 2A). Northern blot analysis confirms that the highest amount of $t$ lk transcript is present during the early syncytial phase of embryonic development, when rapid DNA replication and chromatin assembly occur (data not shown). Moreover, ubiquitous expression of $t$ lk is found in proliferative tissue, the larval imaginal discs (data not shown).

To examine the cellular localization of Drosophila Tousled-like kinase protein (TLK), we generated antibodies against TLK (see Materials and Methods). In Western blots prepared from crude extracts of freshly laid eggs or nuclei of embryos (Fig. 2B), anti-TLK antibodies recognize two bands of $\sim 135$ and $125 \mathrm{kD}$, the predicted size of TLKs. In addition, the antibodies detect two smaller bands. All bands are absent from corresponding crude extracts of $t \mathrm{k}^{\Delta 14}$ mutants (see below), indicating that anti-TLK antibodies are specific and have no cross-reactivity. The two smaller bands seen in the Western blots (Fig. 2B) likely represent TLK degradation products.

Early proliferation events during Drosophila embryogenesis proceed through 13 rapid and synchronous syncytial mitotic cycles. After cellularization, which occurs during nuclear division cycle 14, cells enter an extended G2 phase. Cells that continue to divide are restricted to so-called mitotic domains (Foe 1989). Immunostaining detects TLK during nuclear division cycle 10, when nuclei align at the periphery of the embryo, in a distinct cell cycle-dependent localization pattern. TLK is strongly enriched in interphase nuclei (Fig. 2C). During all other stages of mitosis, TLK is not associated with the mitotic chromosomes, but rather, diffusely distributed throughout the cells (data not shown; Fig. 2D). After cellularization, when the mitotic domains of the embryo have formed, and throughout embryonic development (Foe 1989|, TLK again becomes enriched only in interphase nuclei (Fig. 2D).

The subcellular pattern of TLK during interphase suggests that the protein could be linked to chromatin. To test this hypothesis, we examined polyploid salivary glands of larvae. We found that the protein is enriched in salivary gland nuclei, in which it concentrates around the polytene chromosomes (Fig. 2E,F). However, no staining was obtained with squashed polytene chromosomes (data not shown). This observation indicates that 
Carrera et al.

Figure 1. Characterization of the $t$ lk gene, tlk mutations, and $t 1 k$ protein. $(A)$ Structure of the $t$ lk gene and position of the P-element insertion 1(1)G0054. cDNA was obtained from the $L D 15160$ clone. AE refers to the contig number of the Drosophila genome project (Adams et al. 2000). Comparison of different $t$ lk cDNA sequences and tlk genomic sequences (Berkeley Drosophila Genome Project, BDGP) showed that tlk encodes differentially spliced transcripts. The tlk LD15160 and GH07910 transcripts differ in their $3^{\prime}$ untranslated region (different polyadenylation sites), and they have an alternatively spliced first exon. The predicted protein sequences encoded by t1k LD15160 and tlk GH07910 (gene CG2829) share a common ORF of 1242 residues and differ in the first putative 13 (MPVVKQRKMSRFK) and 24 amino acids (MDQFQTSLNPRKL ELLESRITGVR), respectively. Database searches revealed that cDNAs LD16185 and LD09833 also encode a protein with 12 alternative $\mathrm{N}$-terminal residues (MCVQKD MRRLKK) and the cDNAs LD41810 and LD16882 lack the alternatively spliced first exon. The alleles $t 1 k^{\Delta 14}$ and $t 1 k^{\Delta 40}$ result from an imprecise excision in which $2357 \mathrm{bp}$ have been deleted $\left(t 1 k^{\Delta 14}\right)$ and $1143 \mathrm{bp}$ have been replaced by a 22-bp sequence interval of the P-element $\left(t l k^{\Delta 4 O}\right)$, respectively. Nontranslated regions and coding region of the gene are shown by open and black boxes, respectively; deleted genomic DNA of the mutants is shown by brackets. PK indicates the cDNA region that encodes the $t l k$ kinase domain; ABP (green box) indicates the position of the peptide used for antibody production. (B) Alignment of the conserved C terminus containing the Tousled kinase domain of Drosophila tlk, Arabidopsis (Atha), and human homologs (Hsap TLK1 and Hsap TLK2) using the CLUSTALW program (Thompson et al. 1994). Identical residues or conservative replacements are shaded; dots denote gaps in the alignments. The amino acid position 217 is labeled with an asterisk; A indicates that the $t 1 k^{\text {dead }}$ transgene carries a replacement of the aspartic acid residue by alanine. (C) Schematic representation of Drosophila, Arabidopsis, and human TLKs. The kinase domains ( $\mathrm{PK}$; yellow boxes), nuclear localization signals (red oval), leucine zipper motives (blue boxes), coiled-coil regions (green spirals), and glutamine-rich regions (green boxes) are shown. Numbers refer to positions of amino acids.

TLK is not associated directly with DNA and may stay in only weak contact with the interphase chromatin of polytene chromosomes.

tlk is an essential gene

To assess the in vivo function of TLK, we generated mutant $t 1 k$ alleles by $P[1 a c W]$-element insertion mutagen-

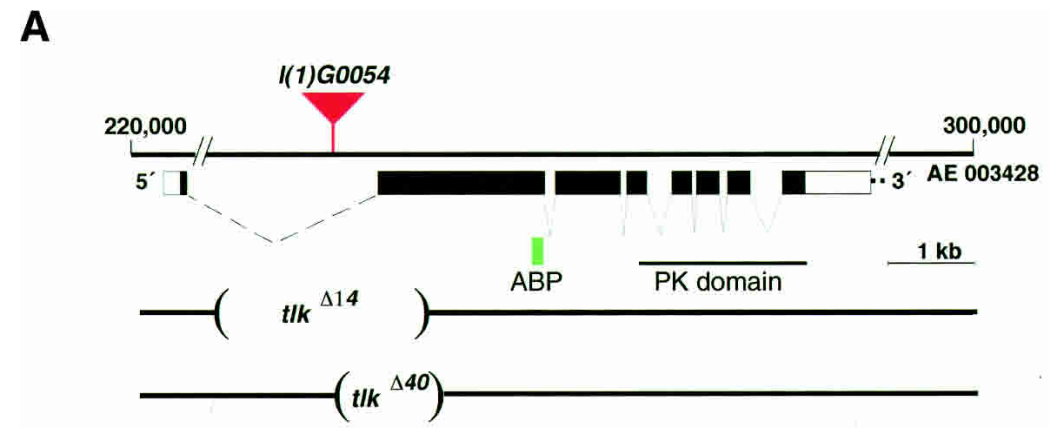

B

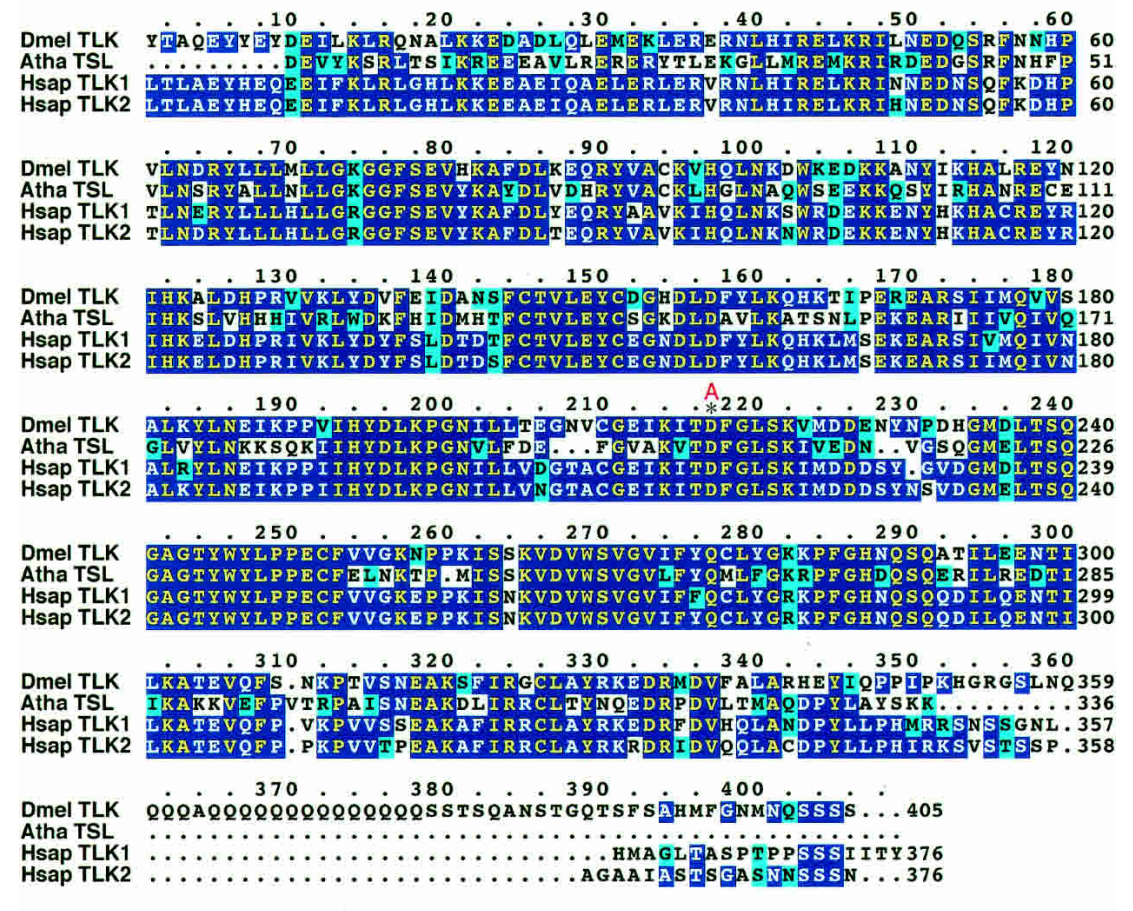

C
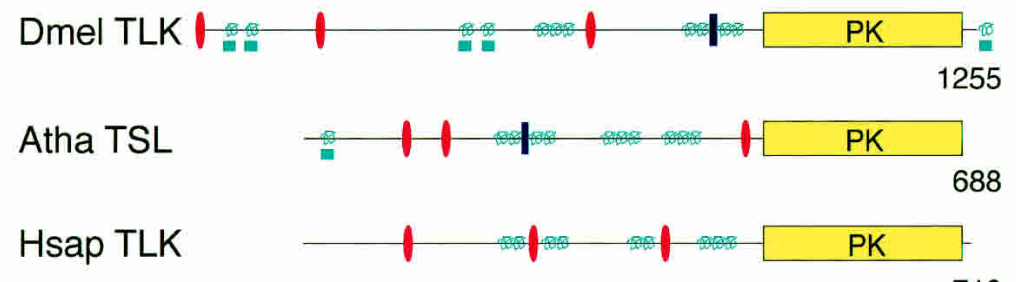

718 
with the original $t 1 k^{1(1) G 0054}$ allele, the homozygous $t 1 k^{\Delta 14}$ and $t 1 k^{\Delta 40}$ mutant individuals die during larval stages. The fact that $t 1 k^{\Delta 14}$ and $t 1 k^{\Delta 4 O}$ mutations lack parts of the TLK coding sequence (Fig. 1A) and fail to express detectable amounts of protein as shown by antiTLK antibody staining on Western blots of crude extracts of eggs from females containing $t 1 k^{\Delta 14}$ germ-line clones (Fig. 2B) indicate that the two alleles are loss-of-function alleles and that $t 1 k^{\Delta 14}$ is possibly amorphic. These data indicate that $t 1 k$ wild-type activity is necessary for the viability of the organism, and that the activity of maternally derived $t$ lk transcripts is possibly sufficient to carry the mutant individuals throughout and beyond embryogenesis (Fig. 2A).

To address the role of maternal tlk transcripts, we used the FLP-ovoD system (Chou and Perrimon 1996) to generate homozygous $t l k$ mutant germ-line clones, which causes the loss of maternal $t$ lk activity in embryos. Male progeny derived from the $t 1 k^{1(1) G 0054}$ mutant female germ line died during embryogenesis, whereas the female individuals, which received a paternal wild-type $t$ lk gene copy, developed into fertile adults. This result indicates that maternally derived $t l k$ activity has an essential function, which can be compensated for by zygotic, paternally derived $t l k$ activity.

Corresponding experiments with $t 1 k^{\Delta 14}$ and $t 1 k^{\Delta 40}$ alleles resulted in embryonic lethality of both males and heterozygous females, showing that these mutants are stronger than the $t 1 k^{1(1) G 0054}$ allele. At $25^{\circ} \mathrm{C}$, females with germ-line clones for both $t 1 k^{\Delta 14}$ and $t 1 k^{\Delta 40}$ mutations are sterile, laying a small number of eggs that collapse shortly after deposition. At $18^{\circ} \mathrm{C}$, however, these females lay eggs that look normal, but a substantial portion of them appears to be shorter than wild type.

$t 1 k^{\Delta 14}$ mutant embryos fail to hatch, and about twothirds die during the first nine nuclear divisions (class I embryos). The other embryos form a syncytial blastoderm and only $12.5 \%$ (of total embryos) initiate gastru-

Figure 2. Distribution of $t$ lk transcripts and protein. $(A)$ In situ hybridization of whole-mount preparations from embryos (stages 3 and 9) as revealed by antisense RNA corresponding to LD15160. (B) Western blots of SDS gels loaded with crude extracts from eggs of either wild-type females (WT) or females containing a homozygous $t l k^{\Delta 14}$ germ line $\left(t l k^{14}\right)$ were probed with anti-TLK antibodies; anti-actin antibodies were used to monitor the protein loading. Asterisks indicate bands corresponding to predicted sizes of TLKs, dots indicate possible degradation products (for details, see text). $(C, D)$ Confocal images of embryos showing DNA (green; SYTOX Green), lamin (red; antilamin antibodies), or TLK (blue; anti-TLK antibodies). (C) Stage 5 wild-type embryo with synchronized nuclei at interphase; TLK is concentrated in the nuclei (see enlarged area, right). (D) Stage 8 wild-type embryo with asynchronous cell divisions. TLK is enriched in interphase nuclei. During all other stages of the division cycle, TLK is distributed diffusely and not associated with condensed chromosomes (enlarged area, right). (E) Staining of whole-mount salivary glands for TLK (green) and DNA (blue). Note that TLK is concentrated in nuclei. $(F)$ Magnification of nuclei showing that TLK is not associated with polytene chromosomes but concentrated around them. lation (class II embryos). $t k^{\Delta 40}$ is a weaker allele, because about half of the embryos gastrulate $152 \%$ of the total embryos), and some of them even develop into hatching larvae.

Loss of tlk affects nuclear divisions and causes DNA fragmentation

Closer examination of aged $t 1 k^{\Delta 14}$ class I embryos revealed that no DNA could be detected in most of them (data not shown). Those containing DNA have a few en-
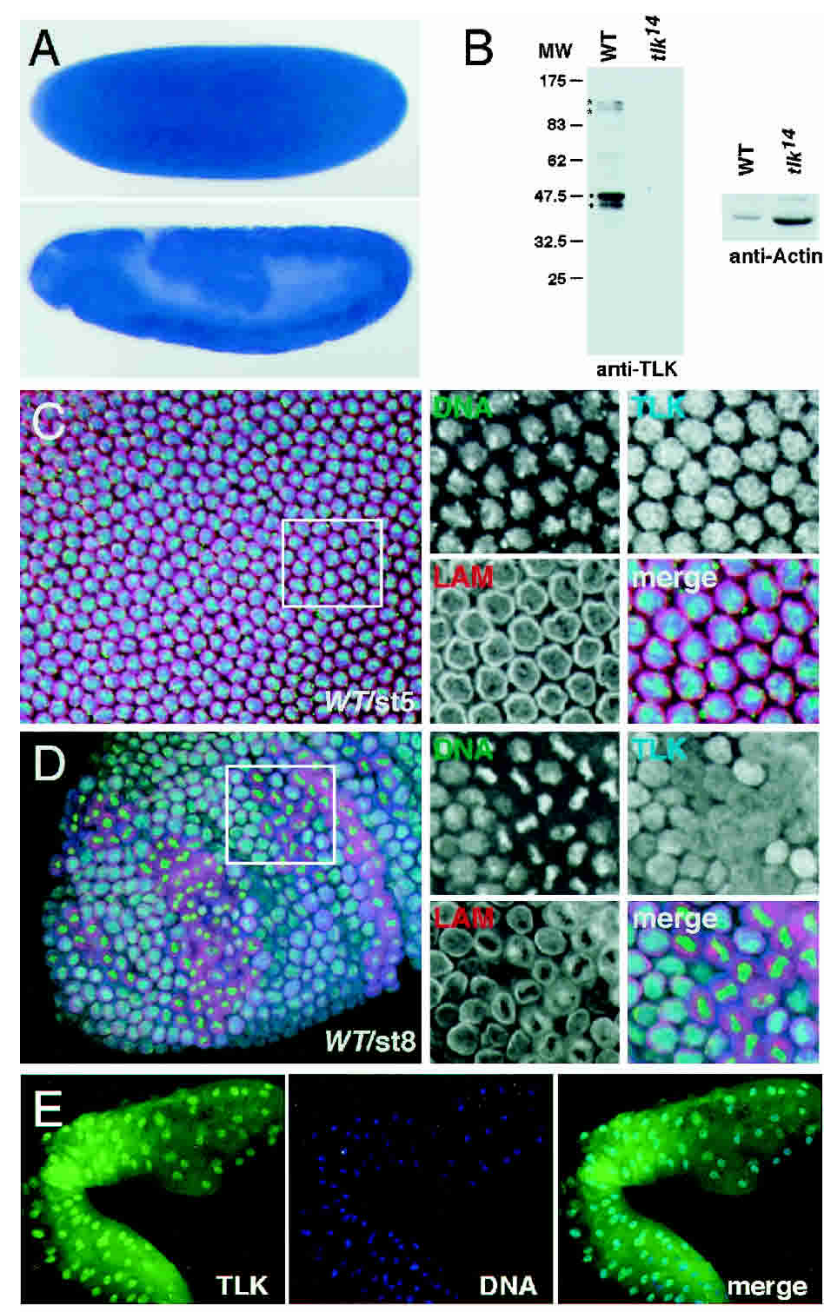

WT/st8
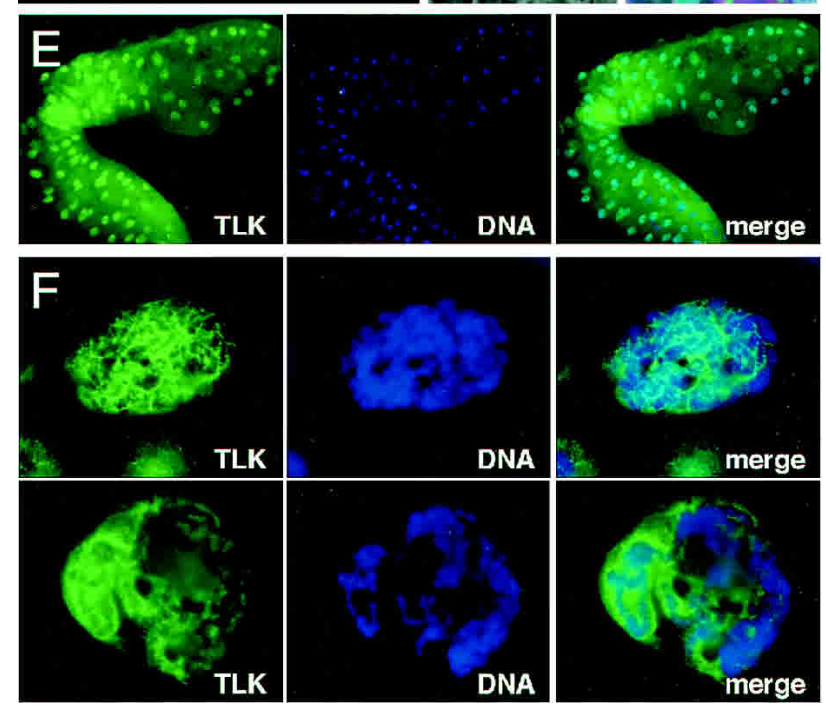
Figure 3. Apoptosis in $t k^{\Delta 14}$ class I mutant embryos. DNA staining with SYTOX Green of preblastodermal wild-type $(A, C)$ and $t l k^{\Delta 14}$ loss-of-function mutant embryos $(B, D)$. Nuclei fail to replicate properly and undergo apoptosis. $(E-G)$ DNA and lamin double staining shows DNA fragmentation and nuclear membrane breakdown in $t 1 k^{\Delta 14}$ mutant embryos, both characteristics of apoptotic death. The nuclear envelope is outlined with antibodies against lamin (LAM; white in $F$, red in $G$ ).

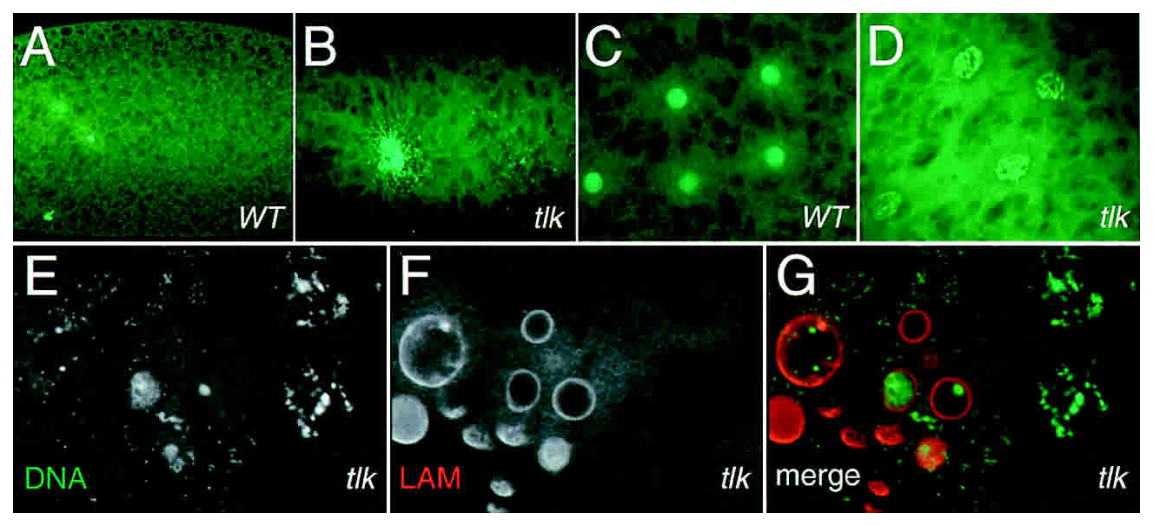

larged nuclei, in which DNA forms either unstructured supernovas (Fig. 3A,B) or network-like structures (Fig. $3 \mathrm{C}, \mathrm{D})$. The latter observation reflects apoptotic nuclei as revealed by TUNEL staining (data not shown), visualization of DNA fragmentation, and nuclear envelope breakdown, as detected by anti-lamin antibodies (Fig. 3E-G). The network-like DNA structures suggest defects in chromatin structure as has been reported for JIL-1 kinase (Wang et al. 2001). These results indicate that loss of maternal tlk activity impairs the early nuclear divisions of class I embryos and leads to apoptotic death.

Although nuclei of class II embryos divide and migrate in a wild-type-like fashion toward the periphery, they harbor a number of distinct defects. The early nuclear divisions are asynchronous, as revealed by the appearance of both interphase and anaphase nuclei that is rarely observed in wild-type embryos (Fig. 4A,B). Furthermore, nuclei are connected by elongated DNA bridges (Fig. 4A-D), indicating incomplete chromosomal segregation. Moreover, nuclei are heterogeneous in size (Fig. 4D, inset) and the DNA of the enlarged nuclei has a uniform cloudy appearance with some strongly stained DNA spots (data not shown).

The early stages of Drosophila embryogenesis undergo a rather specialized division cycle, with nuclei cycling between $\mathrm{S}$ and $\mathrm{M}$ phases only, for example, lacking the $\mathrm{G}$ phases in between. To find out whether TLK is also important for proliferating tissues that follow a conventional cell cycle, we performed mitotic recombination experiments to generate homozygous tlk mutant cells during imaginal disc development (Dang and Perrimon 1992). We found that imaginal disc cells homozygous for $t 1 k^{\Delta 14}$ mutant are able to initially form clones of up to eight cells and then disappear from the growing tissue, whereas the wild-type twin clones continue normal growth (data not shown). These observations confirm that loss of $t l k$ activity causes cell death.

\section{tlk mutants show a reduced level of phosphorylated histone $\mathrm{H3}$}

TLK1 was shown to phospholylate Ser 10 of histone H3 and to substitute for the absence of Ipl1, a kinase required for histone $\mathrm{H} 3$ phosphorylation in yeast ( $\mathrm{Li}$ et al.
2001). We therefore asked whether the amount of histone $\mathrm{H} 3$ phosphorylation is altered in tlk mutant embryos. Figure 5A-F show that $t 1 k^{\Delta 14}$ mutants have only a low number of nuclei that are stained with antibodies directed against phophorylated histone $\mathrm{H} 3$, a molecular marker of M-phase nuclei (Hendzel et al. 1997). This indicates that the majority of $t$ lk mutant nuclei remain in interphase, and only a few continue mitosis (Fig. 5AF). Reduced levels of phophorylated histone H3 in $t 7 k^{\Delta 14}$ mutants could be confirmed by Western blot analysis, showing that although $t l k^{\Delta 14}$ and wild-type embryos contain similar amounts of histone $\mathrm{H} 3$, the amount of phosphorylated histone $\mathrm{H} 3$ in $t l k^{\Delta 14}$ mutants was reduced significantly (Fig. 5G). It is noteworthy that we
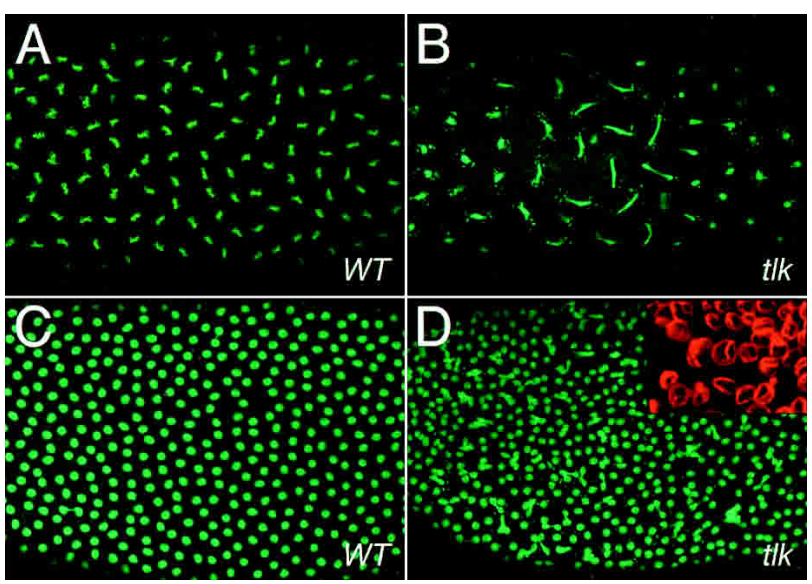

Figure 4. Asynchronous nuclear divisons in $t \mathrm{k}^{\Delta 14}$ class II mutant embryos. DNA is stained with SYTOX Green (DNA; green in $A-D \mid$. The nuclear envelope is outlined with antibodies against lamin (LAM; inset, D). (A) Synchronous nuclear divisions (here: metaphase) in a preblastoderm wild-type embryo. (B) $t 1 k^{\Delta 14}$ mutant embryo of younger age showing that nuclear divisions are asynchronous. Note that nuclei at the left and right margins have already divided and are separated, whereas nuclei in the central region are still in anaphase and show a defective chromosome segregation pattern (long DNA bridges). $(C, D)$ Nuclear cycle 12 wild-type $(C)$ and corresponding $t 1 \mathrm{k} \mathrm{mu-}$ tant embryo $(D)$. Note the loss of mitotic synchrony and uneven spacing of mutant nuclei (inset, D). The nuclear envelope is labeled with antibodies against lamin (red). tlk embryos show heterogeneity in the size of the nuclei. 


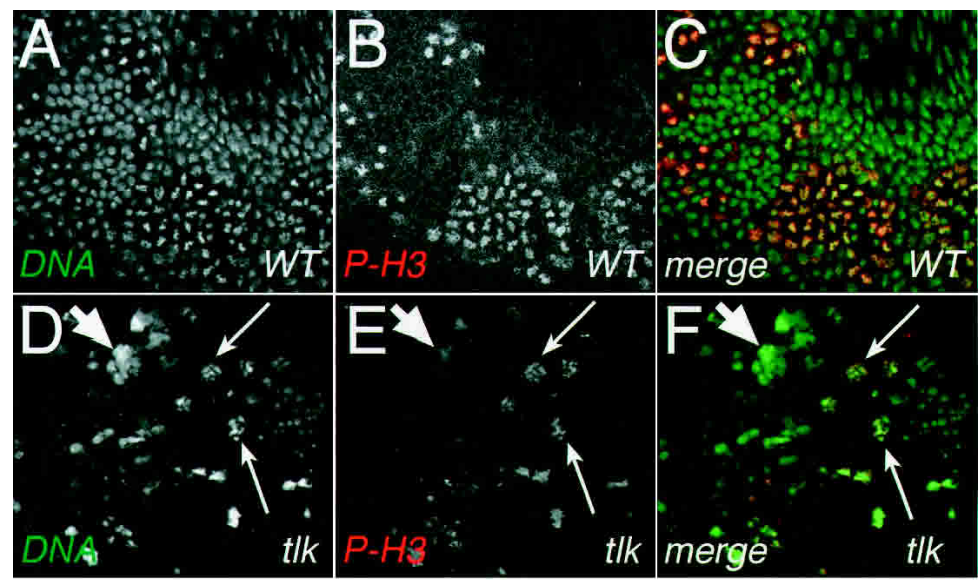

G

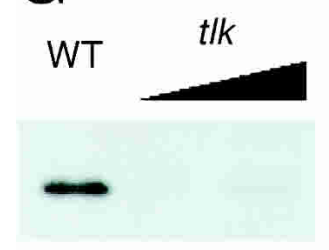

anti-phospho $\mathrm{H} 3$

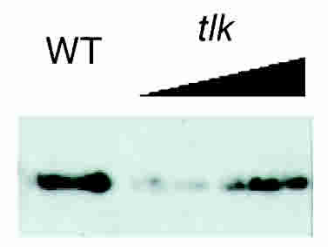

anti-histone $\mathrm{H} 3$

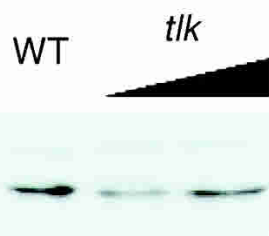

anti-Actin
Figure 5. $t l k^{\Delta 14}$ mutants have reduced phosphorylated histone H3 levels. DNA is stained with SYTOX Green (DNA; white in $A, D$; green in $C, F)$. Nuclei in $M$ phase are visualized by staining with anti-phospho-histone $\mathrm{H} 3$ antibody $(\mathrm{P}-\mathrm{H} 3$; white in $B, E$; red in $C, F) .(A-C)$ DNA and phosphorylated histone $\mathrm{H} 3$ patterns in stage 8 wild-type embryos. Note P-H3 antibody stained cells within the mitotic domains. $(D-F) t 1 k^{\Delta 14}$ mutant embryo stained with P-H3 antibody. Note few mitotic cells undergoing DNA fragmentation (large thin arrows). Most nuclei remain in interphase and accumulate big clumps of DNA (small fat arrows). $(G)$ Western blots of SDS gels loaded with crude extracts from eggs that derived from either wild-type females (WT) or females containing homozygous $t k^{\Delta 14}$ germ lines were probed with antibodies against phosphorylated histone H3 (anti-phospho H3). Controls for loading of protein extracts; antibody staining of nonphosphorylated histone $\mathrm{H} 3$ (anti-histone $\mathrm{H} 3$ ) and actin (anti-Actin); increasing amounts of the protein extracts are indicated by triangles. Note that the $t l k^{\Delta 14}$ mutants show reduced levels of phosphorylated histone H3. failed to detect increased levels of histone $\mathrm{H} 3$ phosphorylation in embryos that overexpressed TLK /data not shown). Reduced levels of phosphorylated histone $\mathrm{H} 3$ in $t l k^{\Delta 14}$ mutants could be an indirect consequence of fewer cells entering mitosis. In summary, these results show that the loss of $t$ lk activity causes the nuclei to arrest in interphase. Those nuclei that are capable of entering the next division cycle fail to segregate chromosomes properly and subsequently undergo apoptosis.

\section{Increased tlk activity alters the pattern of cell proliferation}

We next asked whether increasing tlk expression also matters to dividing cells. To answer this question, we used the GAL4/UAS system (Brand and Perrimon 1993) to examine the effects of transgene-dependent $t$ lk overexpression throughout the early embryos. Overproduction of $t$ lk in response to some of the most active Gal4 drivers during early embryogenesis such as V32-Gal4, arm-Gal4, and en-Gal4 (see Materials and Methods) results in embryonic lethality. MS1096-driven overexpression (Milan et al. 1998) of $t$ lk in the dorsal compartment of wing imaginal discs results in fewer and enlarged cells (data not shown). These findings are consistent with the conclusions drawn from the loss-of-function mutant analysis, showing that the level of TLK activity plays a general and provital role during the cell cycle and thereby affects proliferating tissues.

\section{TLK interacts with ASF1 in vivo}

Studies on human TLKs have shown that they are able to phosphorylate ASF1, a histone chaperone involved in chromatin assembly (Silljé and Nigg 2001). Thus, the tlk-dependent nuclear division defects in Drosophila might be mediated by ASF1 and thereby affect the chromatin assembly pathway. Therefore, we investigated whether TLK and ASF1 interact functionally in vivo by gain-of-function experiments, in which tlk and asf1 were expressed in response to the eyeless-Gal4 (ey-Gal4) driver during eye development. Figure 6A shows that overexpressing $t l k$ or asf1 alone results in mild rougheye phenotypes, whereas the coexpression of both genes causes a dramatic effect. Most of the derivatives of the eye-antenna imaginal disc fail to develop, resulting in a so-called pin-head phenotype (Fig. 6A). The enhancement of the phenotype due to the combined expression of asf 1 and tlk strongly suggests that the products of the two genes act either in the same genetic pathway or contribute to the same process in an independent fashion.

To further establish whether asf1 and tlk act in the same genetic pathway, we performed a complementary experiment, in which we coexpressed ASF1 and a dominant negative variant of TLK (TLK ${ }^{\text {dead }}$ ), which contains a single amino acid replacement (D to A, position 217 of the catalytic domain; Fig. 1B). Overexpression of $t k^{\text {dead }}$ in response to ey-Gal4 had a devastating effect on eye development, leading to a pin-head phenotype, as observed in response to the combined overexpression of $t$ lk and asf1 (see above; Fig. 6A). Interestingly, expression of asf1 in addition to $t k^{\text {dead }}$ significantly suppressed the effect of $t k^{\text {dead }}$ (Fig. 6A). Suppression of the $t 1 k^{\text {dead }}$ effects by coexpression of asf1 is not due to the dilution of the Gal4 driver, because coexpression of the flippase enzyme does not suppress the effects of $t 1 k^{\text {dead }}$ overexpression. These findings show that asf1 overexpression is 
Figure 6. TLK acts in the same genetic pathway as ASF1 and phosphorylates it in vitro. (A) tlk interacts with asf1 in vivo. In wild-type flies, synchronized cell divisions give rise to adult eyes with regularly distributed facets. In flies overexpressing either tlk kinase or asf1 in the eye under the control of eyeless-GAL4 driver, the facets distribution is slightly altered, giving rise to a rough eye phenotype. Coexpression of both tlk and asf1 in the eye using the eyeless-GAL4 driver leads to severe developmental defects, resulting in pin-head phenotype. Overexpression of $t 1 k^{\text {dead }}$ alone in the eye with the same eyeless-GAL4 driver results in pin-head phenotype, whereas coexpression of both $t l k^{\text {dead }}$ and asf1 rescues the $t 1 k^{\text {dead }}$ pin-head phenotype. (B) GST pull-down assays with radiolabeled TLK and $\mathrm{TLK}^{\text {dead }}$ produced by coupled in vitro transcription/translation (IVT) in the presence of $\left[{ }^{35} \mathrm{~S}\right]$ methionine as detected by autoradiography. Both TLK and TLK ${ }^{\text {dead }}$ bind to GST-ASF1 fusion protein, but not to GST. A total of $10 \%$ of the input mixture was loaded as control (Input). A major fraction of TLK kinase $(\mathrm{P})$ migrates slower on SDS-PAGE compared with TLK ${ }^{\text {dead }}$ due to autophosphorylation. $(C)$ Stability of the interaction between TLK and ASF1 depends on TLK's autophosphorylation state. Radiolabeled TLK and TLK ${ }^{\text {dead }}$ were treated with either calf intestinal alkaline phosphatase (CIP) or with ATP. CIP treatment results in a fast migrating TLK form of same mobility as TLK ${ }^{\text {dead }}$, which is pulled down by GST-ASF1. Addition of ATP results in a slower migrating form of TLK, which is presumably hyperphosphorylated (labeled PP) and does not bind GST-ASF1. Gel mobility of TLK ${ }^{\text {dead }}$ and binding to GST-ASF1 protein is unchanged after treatments either with CIP or ATP. (D) Nonradiolabeled, in vitro translated TLK phosphorylates GST-ASF1 protein and itself, but not GST alone, as detected by autoradiography with ${ }^{32} \mathrm{P}$. TLK ${ }^{\text {dead }}$ lacks phosphorylation and autophosphorylation activities because of a mutation in the catalytic domain. TLK and TLK ${ }^{\text {dead }}$ proteins were not synthesized in sufficient amounts to be revealed by Coomassie staining; however, they were revealed by immunoblotting using anti-TLK antibodies (data not shown).

able to inactivate TLK ${ }^{\text {dead }}$ dominant negative function. Taken together, these coexpression studies suggest that in vivo ASF1 is a substrate of TLK.

\section{TLK binds and phosphorylates ASF1 in vitro}

One possibility to explain the ASF1-dependent suppression of the dominant negative effect of $\mathrm{TLK}^{\text {dead }}$ is to suppose that, like in humans (Silljé and Nigg 2001), ASF1 is able to form a stable complex with the mutated kinase, and thereby suppresses its action by competitionbased dilution of the active molecule.

To test this hypothesis and to further characterize the interaction between TLK and ASF1, we performed GST pull-down experiments. We found that bacterially produced GST-ASF1 fusion protein is able to pull down TLK or TLK ${ }^{\text {dead }}$ synthesized and radiolabeled by in vitro transcription/translation (IVT) reaction (Fig. 6B). TLK produced in vitro migrates in two forms (slow and fast migrating; Fig. 6B,C), TLK ${ }^{\text {dead }}$ migrates only as the fast moving form (Fig. 6B,C). These observations raise the possibility that in vitro synthesized TLK is phosphorylated, possibly by autophosphorylation. Figure 6D shows that in vitro synthesized TLK is active and able to phos- phorylate both the GST-ASF1 fusion protein and itself. Treatment of TLK preparations with phosphatase or ATP further confirms that the fast and slow moving forms differ in phosphorylation status and provide insights into the interactions between ASF1 and TLK. We find that upon treatment with ATP, TLK migrates even slower (probably due to hyperphosphorylation) and is not pulled down by the GST-ASF1 fusion protein (Fig. 6C). We noted that ATP treatment may also alter the binding of ASF1 to hypophosphorylated TLK, as the recovery of the fast-migrating protein band seems to be reduced (Fig. 6C). This could be due to continued TLK autophosphorylation during the binding reaction or to partial ASF1 phosphorylation that may alter the interaction with TLK. In contrast, upon phosphatase treatment, TLK migrates only as the fast moving form and forms a stable complex with the GST-ASF1 fusion protein. Phosphatase or ATP treatments have no effects on TLK ${ }^{\text {dead }}$ and do not alter its ability to interact with the GST-ASF1 fusion protein (Fig. 6C). These data suggest that ASF1 binds dephosphorylated (or moderately phosphorylated) TLK and dissociates upon TLK hyperphosphorylation. In addition, phosphorylation of ASF1 may regulate the interaction. 
TLK and ASF1 affect chromatin structure and DNA replication

To gain further insight into the processes regulated by the TLK-ASF1 pathway during development, we have generated individuals in which UAS-asf1 and/or UAStlk transgenes can be ubiquitously activated. Because early acting GAL4 drivers cause embryonic lethality, we used heat-shock inducible GAL4 drivers. We found that 2-h heat-shock at any time during larval development caused UAS-asf1 or UAS-tlk-dependent lethality. We therefore decided to take advantage of the fact that the heat-shock promoter (hsp70) is leaky, and we determined the experimental conditions $\left(25^{\circ} \mathrm{C}-30^{\circ} \mathrm{C}\right.$; see Materials and Methods) under which larvae developed into adult flies. Under these conditions, the overall growth and differentiation of larvae is not affected by expressing either asf1, tlk, or $t l^{\text {dead }}$, whereas the size of the third instar salivary glands is greatly reduced. The reason for the enhanced or even specific effect of ASF1 and TLK on salivary gland nuclei is that, in contrast to most other larval tissue, they undergo 10 rounds of endoreplication, in which DNA is replicated without daughter strands separation. Lack of endoreplication, therefore, would cause significantly smaller nuclei, and in turn, smaller salivary glands.

During normal salivary gland growth, endoreplication gives rise to polytene chromosomes showing a characteristic pattern of chromosomal bands. Polytene chromosomes provide a prime model to study in vivo the structure of interphase chromatin. Overexpression of ASF1 and/or TLK had severe effects on the morphology and the size of nuclei of salivary glands (Fig. 7). EGFP, which serves as an internal control for the overexpression of a protein in response to heat-shock-induced Gal4, had no such effect (Fig. 7A,G). Overexpression of asf1 results in smaller salivary glands composed of fewer cells (Fig. 7B), which contain chromosomes that are reduced in size (Fig. $7 \mathrm{H})$. These findings suggest that excess of ASF1 slows down cell cycle progression or leads to cell death and that overexpression of ASF1 interferes with endoreplication. In the case of $t$ lk overexpression, the salivary glands are also smaller, but the cell number is not significantly reduced, suggesting that the reduced size seems to be due primarily to reduced endoreplication, leading to thinner chromosomes than in wild-type and ASF-overexpressing glands (Fig. 7I; cf. Fig. 7G, H; see also Fig. $7 \mathrm{H}$ ). In addition, tlk overexpression alters higher-order chromatin structures, as the chromosomes are grossly disrupted, losing their typical banding pattern (Fig. 7I). These observations suggest that TLK is essential for the proper assembly of higher order chromatin structures.

Coexpressing asf1 and tlk together aggravates the salivary-gland mutant phenotypes as compared with overexpression of either asf 1 or tlk only. Under these conditions, salivary glands are composed of only a few cells (Fig. 7D) that contain strongly underreplicated DNA (Fig. 7J). As observed with the eye (see above), overexpression of $t \mathrm{k}^{\text {dead }}$ affects salivary gland development severely, that is, we could only recover individuals with salivary glands by growing the larvae at $18^{\circ} \mathrm{C}$. These glands are composed of only a few cells, all with underreplicated polytene chromosomes. This finding shows that the presence of $t \mathrm{k}^{\text {dead }}$ strongly inhibits endoreplication and interferes with cell divisions or cell viability (Fig. 7E,K). The effect of $t l k^{\text {dead }}$ overexpression can be suppressed by coexpression of asf1 (Fig. 7F,L), confirming an interaction between ASF1 and TLK. Despite a strong effect on chromatin structure and endoreplication in salivary glands, larvae overexpressing either asf1 and/or tlk at $30^{\circ} \mathrm{C}$ (hsp-driver) are able to develop into adults that, however, lack a number of the large thoracic bristles (macrochaetae). Also, the sex ratio of the flies hatching in these overexpression studies was skewed toward females, indicating that males are more sensitive to the altered levels of tlk and asf1 (data not shown). Altogether, these data imply that the TLK-ASF1 pathway is important for both DNA replication and chromatin assembly, suggesting a mechanism by which TLK controls cell cycle progression.

\section{Discussion}

The $t$ lk gene encodes a conserved serine/threonine kinase with homologs in plants and animals. In humans, the TLKs are activated during the $S$ phase of the cell cycle and were shown to phosphorylate at least two targets, ASF1 (Silljé et al. 1999; Silljé and Nigg 2001) and histone H3 (Li et al. 2001). ASF1 acts as a histone chaperone and participates in replication-dependent chromatin assembly (Tyler et al. 1999). Phosphorylated histone $\mathrm{H} 3$ is an important factor in the condensation of chromatin during mitosis (Wei et al. 1999). These discoveries revealed a possible link between the TLK family members and regulation of chromatin condensation and/or the assembly of chromatin during cell cycle progression. More recently, TLK activity has been shown to be downregulated upon exposure to DNA-damaging ionizing radiation during $S$ phase, a response depending on ATM and Chk1 kinases (Groth et al. 2003).

We show that Drosophila tlk is essential for nuclear divisions and cell viability, and required for the maintenance of the higher-order chromatin structure of interphase chromosomes. We also demonstrate that Drosophila TLK phophorylates ASF1, and that both proteins cooperate in the control of chromatin replication in vivo, suggesting a mechanism that links cell proliferation and a TLK-dependent chromatin assembly pathway.

\section{TLK is essential for nuclear divisions and cell viability}

The Drosophila tlk gene is transcribed throughout development in both somatic and germ-line tissues. Its activity is essential for survival as required for normal nuclear divisions in proliferating tissues. Loss of tlk causes an arrest of cell cycle progression at interphase and subsequently leads to apoptotic death.

Nuclear division defects are already detected in early embryos that lack tlk. Normally, early Drosophila em- 
bryos develop in a syncytium, in which the nuclei proceed through rapid nuclear divisions undergoing $S$ and $M$ transitions only. When embryos lack TLK activity, nuclear cleavages stop. In both Drosophila and human cells, TLK is enriched in S-phase nuclei and reaches its maximal activity during $S$ phase (Silljé et al. 1999). These observations suggest that TLK activity is required for proper DNA replication and/or proper chromatin assem-
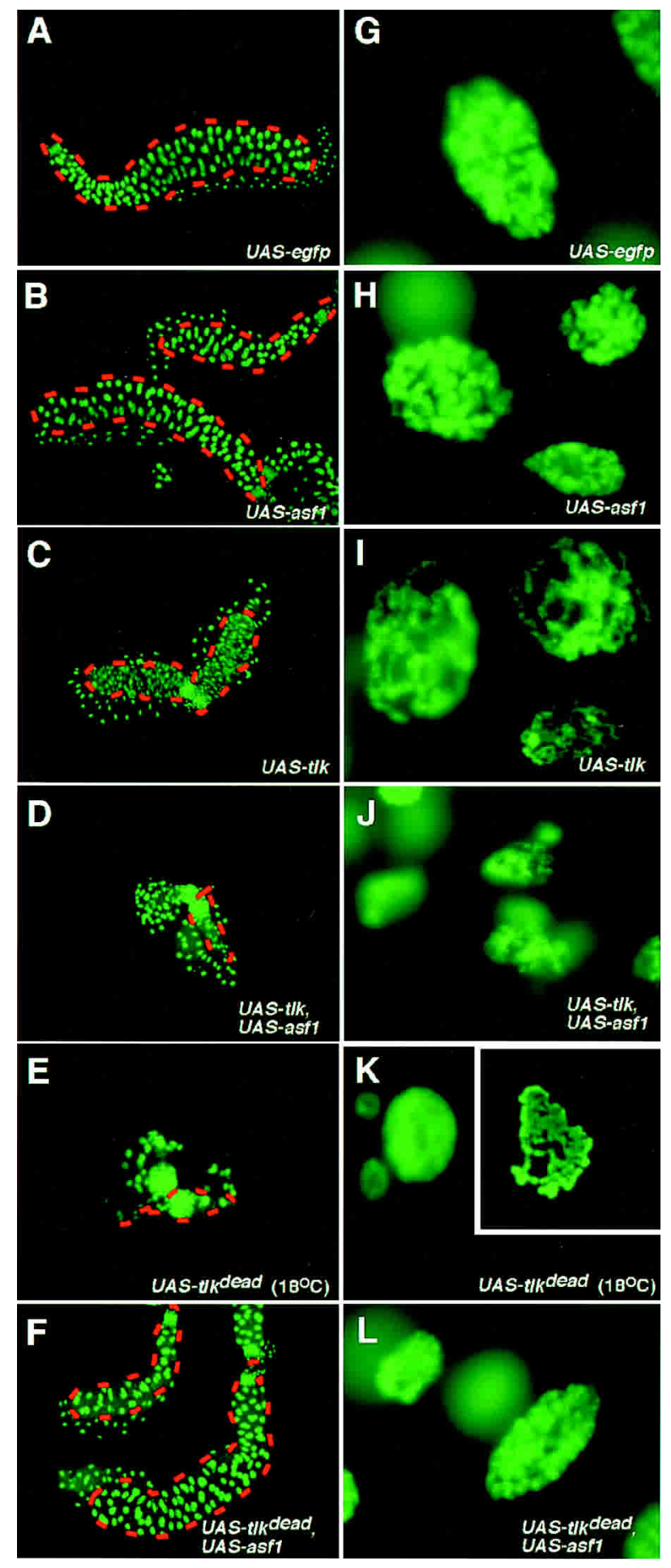

bly. The elongated DNA masses (Fig. 4), however, imply that the most prominent effects occur during anaphase. Therefore, we cannot exclude the possibility that TLK affects not only the replication and chromatin assembly during interphase, but also other steps in the cell cycle (Fig. 8). In humans, TLK also phosphorylates histone H3 (Li et al. 2001), a step thought to be important for progression through mitosis. Although our results support a role of Drosophila TLK in histone H3 phosphorylation (Fig. 5G), they do not demonstrate that histone $\mathrm{H} 3$ is a direct phosphorylation target of TLK.

\section{Chromatin assembly factor ASF1 is a phosphorylation} target of TLK

In support of a role of TLK in controlling the assembly and/or condensation of chromatin, we found that, as in humans (Silljé and Nigg 2001), Drosophila chromatin assembly factor ASF1 is phosphorylated by TLK. However, unlike in humans, in which TLKs interact only transiently with ASF1a and ASF1b (Silljé and Nigg 2001), we found that Drosophila TLK and ASF1 proteins form a stable complex that is disrupted upon TLK hyperphosphorylation. Interestingly, in human, TLK kinase is hyperphosphorylated during $S$ phase, a time point which coincides with maximal TLK activity. Dephosphorylated forms of TLK are found throughout the rest of the cell cycle (Silljé et al. 1999). In light of these observations, we suggest that Drosophila ASF1 stably binds dephosphorylated TLK prior to initiation of DNA replication. During $S$ phase, the initiation of DNA replication probably results in the activation of TLK concomitant to its autophosphorylation and the subsequent release of phosphorylated ASF1 from the complex. Phosphorylated ASF1 may then be used in de novo chromatin assembly coupled to DNA replication. A dynamic mode of the

Figure 7. Overexpression of the TLK-ASF1 pathway affects chromatin structure and endoreplication in salivary glands. $(A, G)$ Salivary glands from larvae overexpressing egfp at $25^{\circ} \mathrm{C}$ under Heat-Shock-gal4 (HS-gal4) driver show normal cell number (128 per lobe) and morphology of polytene chromosomes. $(B, H)$ Overexpression of asf 1 results in smaller salivary glands with only half of the normal cell number (upper salivary gland). Occasionally, some of the salivary glands have normal size and almost normal cell number (lower salivary gland). Polytene chromosomes appear thinner, indicating that DNA is underreplicated. $(C, I)$ Overexpression of $t 1 k$ produces small salivary glands with nearly normal cell number, but with chromosomes that are extremely thin and unstructured, showing global changes in higher-order chromatin structure. $(D, J)$ Coexpression of both tlk and asf1 gives rise to tiny salivary glands with few cells $(\sim 1 / 10$ of the normal) and tiny chromosomes. $(E, K)$ Expression of the dominant negative $t 1 k^{\text {dead }}$ allele almost completely abolishes cell proliferation in salivary glands, even at $18^{\circ} \mathrm{C}$. In these glands, chromosomes appear to be underreplicated. Chromosomes from few preparations that could be obtained show a banded pattern $(K$, inset $)$. $(F, L)$ Coexpressing asf 1 with $t l^{\text {dead }}$ partially rescues $t l k^{\text {dead }}$ effects on cell cycle progression and DNA replication. Note that $G-L$ (with the exception of the inset in $K$ ) are presented at the same magnification. 


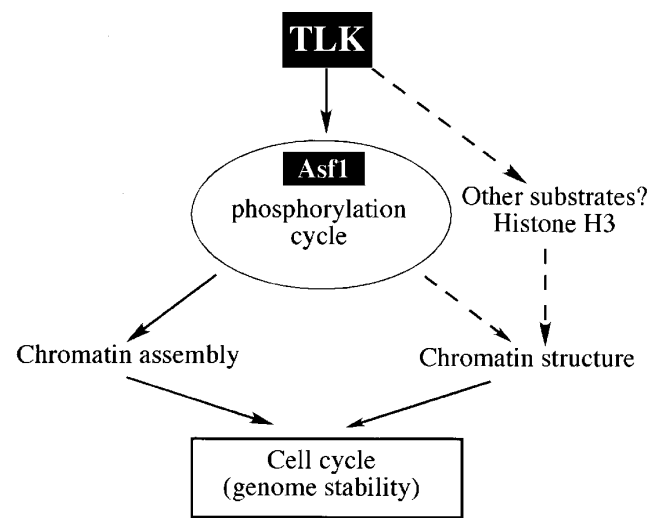

Figure 8. Possible control over cell cycle progression by TLK via chromatin. Altering TLK expression affects cell cycle progression most likely via Asf1. Altered Asf1 phosphorylation could affect chromatin assembly in S phase and/or during DNA repair. TLK may also act on chromatin through histone $\mathrm{H} 3(\mathrm{Li}$ et al. 2001), and have additional functions via as yet unidentified substrates.

TLK-ASF1 interaction may also explain the rather weak association of TLK with polytene chromosomes and the absence of TLK-associated chromosomal bands on squashed chromosomes (Fig. 2E,F).

A similar mechanism has been suggested in yeast for the interactions between the RAD53 checkpoint kinase and ASF1 (Emili et al. 2001). In this case, activation of RAD53 by hyperphosphorylation induced by DNA damage results in the release of ASF1 from the complex. Upon release, ASF1 is thought to function in chromatin assembly on repaired DNA (Emili et al. 2001). However, the yeast ASF1 protein does not seem to be phosphorylated by the RAD53 kinase. In addition, there is no homolog of TLK in yeast, suggesting that the phosphorylation of ASF1, as observed in both humans and fly, is likely to be specific for higher eukaryotes.

It is interesting to note that the C-terminal part of the yeast ASF1 protein is enriched in acidic residues relative to its higher eukaryotic counterparts. This raises the possibility that the phosphorylation of ASF1 in Drosophila and humans adds negative charges to the $\mathrm{C}$-terminal tail of ASF1 to allow fly or human ASF1 to attain a structure similar to that of yeast ASF1. Although, in yeast, an ASF1 protein lacking the polyanionic stretch is sufficient to complement asf1-growth defects and establishment of telomeric silencing in vivo, we believe that the negatively charged protein may enhance the deposition of histones. In support of this hypothesis, it was found that the yeast ASF1 protein lacking the polyanionic tail displayed markedly reduced binding to histones $\mathrm{H} 3 / \mathrm{H} 4$ (Umehara et al. 2002).

\section{TLK and chromatin assembly}

Overexpression of TLK appears to block endoreplication of polytene chromosomes in the salivary glands, further substantiating the role of TLK in DNA replication. By overexpression of both genes, we were able to show that TLK cooperates with ASF1 in this process, arguing that the TLK-dependent effects on endoreplication are mediated through components of the chromatin assembly pathway (Fig. 7). ASF1 in yeast has been found to be important for histone gene regulation (Sutton et al. 2001). In this process, ASF1 cooperates directly with the histone regulation protein (HIR). Studies in which the HIR was up-regulated show that excess of the protein leads to the repression of histone gene transcription, followed by a block of DNA synthesis and an arrest of the cell cycle in S phase (Sharp et al. 2001; Nelson et al. 2002). In addition, the Xenopus laevis homolog of HIR, called HIRA, is able to assemble nucleosomes on naked DNA, suggesting a more general role for HIR proteins in chromatin organization (Ray-Gallet et al. 2002). These findings raise the possibility that TLK affects endoreplication by regulating DNA replication through the ASF1HIR pathway, a proposal that will need to be addressed by future experiments.

TLK is not directly associated with distinct sites on polytene chromosomes, but TLK overexpression significantly disrupts their higher-order chromatin structure (Fig. 7I). Thus, TLK may participate in chromatin assembly and/or condensation by, for example, regulating or modifying chromatin proteins (Fig. 8). Several mutations have been reported that affect the higher-order chromatin structure of polytene chromosomes. Whereas mutations in iswi and nurf301, two genes encoding proteins involved in nucleosome sliding, affect mostly male $\mathrm{X}$ chromosome structure, mutations in the jil-1 kinase and $\mathrm{Su}$ (var)2-10 disrupt the chromatin structure of all polytene chromosomes (Deuring et al. 2000; Hari et al. 2001; Li et al. 2001; Wang et al. 2001; Badenhorst et al. 2002). Within such a scenario, TLK could exert its function in the maintenance of higher-order chromatin structures by modulating the activity of ASF1 or some other chromatin protein during chromatin assembly. Possible mechanisms by which altering TLK activity leads to a disruption of chromatin and cell cycle arrest are summarized in Figure 8.

Although further experiments will be required to determine exactly how TLK-dependent phosphorylation affects cell cycle progression, our findings suggest the existence of a crucial link between cell cycle progression and chromatin structure. First, we show that the lack of TLK activity leads to an arrest of cell cycle progression at interphase, and as consequence, to reduced levels of phosphorylated histone H3. Second, the fact that TLK seems to interact with chromatin, and that the only two known substrates of TLK are proteins involved in chromatin structure (histone H3 in humans and ASF1 in both humans and Drosophila) suggests that TLK activity may be targeted primarily to chromatin proteins. Finally, a closer examination of the chromosomes following TLK overexpression demonstrates that an alteration of TLK activity causes a global change in chromatin structure. These findings raise the intriguing possibility that the lack of proper chromatin structure may be the cause of the cell cycle arrest, and that there might be a specific 
cell cycle checkpoint determining whether the chromatin is properly assembled. In support of this hypothesis, a recent study shows that treating tissue-culture cells with chromatin-modifying drugs activates the ATM kinase, a protein whose activity is thought to lead to the cell cycle arrest following exposure to DNA-damaging ionizing radiation (Bakkenist and Kastan 2003). In addition, altering in vivo chromatin assembly by expressing a dominant negative mutant of the largest CAF-1 subunit induces S-phase arrest through activation of DNAdamage checkpoint pathway (Ye et al. 2003). It is interesting, then, to speculate that the cell cycle arrest following the alteration of chromatin structure due to TLK misregulation may occur through the activation of the DNA damage checkpoint pathway.

\section{Materials and methods}

\section{Isolation and characterization of tlk alleles}

Maintenance and handling of fly stocks and crosses were done according to standard techniques (Peter et al. 2002). 1(1)G0054 is a lethal PlacW insertion in the first intron of tlk (Peter et al. 2002) that was used for subsequent studies. Isolation of new alleles by P-element excision was carried out with jump-starter females [genotype $w t 1 k^{1(1) G 0054} / w F M 6$; TM2 $U b x \Delta 2-3 /+$ ] that were crossed with Y/FM6 males. P-element excisions were scored in female progeny (white-eye phenotype) and crossed with Y/FM7 GFP males, so that progeny can be distinguished on the basis of the visible GFP marker. Of 1250 independent excision events, we established 36 homozygous lethal strains that were balanced over FM7 GFP. The lethal phase of each tlk allele was determined with hemizygous males, genomic DNA surrounding the original 1(1)G0054 insertion site was amplified by PCR and the DNA fragments were sequenced (Peter et al. 2002). Further detailed analysis was done with two deletion alleles, $t l k^{\Delta 14}$ and $t l k^{\Delta 40}$ (see text and Fig. 1).

\section{Generation of germ-line clones}

The alleles $t 1 k^{1(1) G 0054}, t 1 k^{\Delta 14}$, and $t 1 k^{\Delta 40}$ were each recombined onto a chromosome carrying $P\left(w^{+} F R T\right) 101$. Homozygous cell clones were generated by mitotic recombination using the FRT/ FLP system (Dang and Perrimon 1992); germ-line clones were generated using the FLP-ovoD system (Chou and Perrimon 1996). Virgin females of the genotype $w$, tlk, FRT101/FM7 GFP were mated with $w$ ovoD 1 v FRT101/Y; HS-Flp males. Flies were transferred to fresh food once every $24 \mathrm{~h}$, and F1 larvae were heat shocked $\left(37^{\circ} \mathrm{C} ; 2 \mathrm{~h}\right)$ during the second and third instar larval stages to induce mitotic recombination events in proliferating germ cells. Embryos derived from a tlk homozygous female germ line were examined at $18^{\circ} \mathrm{C}$ and $25^{\circ} \mathrm{C}$.

\section{Antibody production, immunocytochemistry, and microscopy}

Rabbit anti-TLK antibodies were generated against the peptide KSQIVGNQKTIDQHKCHIAKC located within the TLK N-terminal domain (position 585-606; Eurogentec). The position of the peptide within the ORF of the TLK coding sequence is indicated in Figure 1A. The cysteine in position 16 of the peptide was modified $\mathrm{C}(\mathrm{t}-\mathrm{Bu})$ to block the coupling in internal positions. Both antiserum and affinity-purified antibodies (Thiopropyl Sepharose 6b, Amersham Pharmacia) were tested with Western blots of nuclear extracts of wild-type and tlk mutant embryos (see Fig. 2B) and by immunostaining of such embryos. Immunoreactivity on Western blots was detected with extracts of wild-type but not of $t l k$ mutant embryos, indicating that the antibodies were specific for TLK. They were used in a 1:1000 dilution. Inmunostainings of wild-type and en-Gal4/UAS-tlk mutant embryos (showing overexpression of TLK in an ectopic stripe pattern) with antibodies against Tousled are fully competed by incubation of the antibody with the peptide antigen at concentrations below $10 \mu \mathrm{g} / \mathrm{mL}$. We also used mouse anti-La$\min$ (1:200), rabbit anti-phospho-histone H3 (1:100; Upstate Biotechnology) as well as Cy3- or Alexa 488-, Alexa 543-, and Cy5or Alexa 633-conjugated secondary antibodies as recommended by the manufacturer (Molecular Probes). For nuclear staining, samples were treated with RNAse A (Sigma; $400 \mu \mathrm{g} / \mathrm{mL}$; 20 min) and incubated with $0.1 \mu \mathrm{M}$ SYTOX Green (Molecular Probes; 2 h). Fixation of Drosophila embryos was in $4 \%$ paraformaldehyde. In general, embryos were incubated with the primary antibodies (PBS; overnight at $4^{\circ} \mathrm{C}$ ), and then with the secondary antibodies and SYTOX Green. Embryos were mounted in VECTASHIELD mounting medium (Vectorlabs) and viewed by confocal microscopy. Digoxigenin-labeled antisense LD15160 RNA was used for whole-mount preparations of ovaries and embryos (Hauptmann and Gerster 1996). Immunostaining of whole-mounted salivary glands or squashed polytene chromosomes were done using a 1:200 dilution of anti-TLK antibody (Platero et al. 1995; Hari et al. 2001). DNA was stained with $1 \mu \mathrm{g} / \mathrm{mL}$ of DAPI.

\section{Overexpression of TLK}

The UAS/GAL4 system was used as decribed (Brand and Perrimon 1993). The UAS-tlk transgene was constructed by inserting the NotI-Asp718 fragment of LD15160, containing the full-length ORF of the $t 1 \mathrm{k}$ cDNA, into the $p U A S T$ vector. The $U A S-t k^{\text {dead }}$ transgene contains a replacement of the aspartic acid residue in position 217 of catalytic domain by alanine (Fig. 1). The UAS-asf1 line was described previously (Moshkin et al. 2002). The UAS-tlk, UAS-tlkdead, and UAS-asf1 lines were crossed with the different Gal4 drivers described in the text. The heat-shock-dependent promoter (hsp70) was used to express the Gal4-dependent $U A S$-asf1 and/or UAS-tlk under conditions that have been described (Moshkin et al. 2002). For details on the driver lines used, see FlyBase (http://flybase.bio. indiana.edu).

\section{GST pull-down}

TLK and TLK ${ }^{\text {dead }}$ were synthesized using rabbit reticulocyte in vitro transcription-translation system (IVT) in the presence of $\left[{ }^{35} \mathrm{~S}\right]$ methionine, as described by the manufacturer (Promega). GST-ASF1 fusion protein was expressed and purified from bacteria (Moshkin et al. 2002). GST pull-down experiments with TLK or TLK ${ }^{\text {dead }}$ were performed for $1-2 \mathrm{~h}$ at $4^{\circ} \mathrm{C}$ in binding buffer (20 mM HEPES-KOH at $\mathrm{pH} 7.6,150 \mathrm{mM} \mathrm{KCl}, 2.5 \mathrm{mM}$ $\mathrm{MgCl}_{2}, 10 \%$ glycerol, $1 \%$ Triton X-100, $1 \mathrm{mM}$ DTT, and 10 $\mathrm{mg} / \mathrm{mL}$ BSA) with GST-ASF1 or GST (negative control) coupled to the Glutathione Sepharose 4B beads (Amersham). Beads were washed three times with 10-bed volumes of buffer $(20 \mathrm{mM}$ HEPES-KOH at pH 7.6; $150 \mathrm{mM} \mathrm{KCl} ; 2.5 \mathrm{mM} \mathrm{MgCl}_{2} ; 1 \%$ Triton $\mathrm{X}-100 ; 1 \mathrm{mM}$ DTT). Proteins were separated on $6 \%$ SDS-PAGE. Bound TLK or TLK ${ }^{\text {dead }}$ were revealed by autoradiography.

\section{TLK autophosphorylation and phosphatase treatments}

For autophosphorylation studies, $\left[{ }^{35} \mathrm{~S}\right]$ methionine radiolabeled IVT-produced TLK or TLK ${ }^{\text {dead }}$ were incubated for $30 \mathrm{~min}$ at 
$30^{\circ} \mathrm{C}$ in TLK kinase buffer $(50 \mathrm{mM}$ Tris- $\mathrm{HCl}$ at $\mathrm{pH} 7.5 ; 10 \mathrm{mM}$ $\mathrm{MgCl}_{2} ; 1 \mathrm{mM}$ EGTA; $0.5 \mathrm{mM} \mathrm{DTT} ; 5 \mathrm{mM} \mathrm{NaF}$ ) in the presence of $10 \mu \mathrm{m}$ ATP (Silljé et al. 1999). Dephosphorylation was performed with $10 \mathrm{U}$ of calf intestinal alkaline phosphatase in supplied buffer (NEB) for $2 \mathrm{~h}$ at $37^{\circ} \mathrm{C}$ (Silljé et al. 1999). Reactions were subsequently diluted in GST pull-down binding buffer and incubated with GST-ASF1 coupled to beads for $1-2 \mathrm{~h}$ at $4^{\circ} \mathrm{C}$. After washes, proteins were separated on 6\% SDS-PAGE and revealed by autoradiography.

\section{In vitro kinase assays}

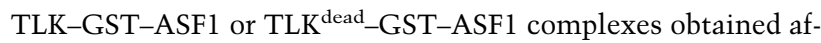
ter GST pull-downs with nonlabeled IVT-produced TLK or TLK ${ }^{\text {dead }}$ were incubated for $30 \mathrm{~min}$ at $30^{\circ} \mathrm{C}$ in TLK kinase buffer in the presence of $10 \mu \mathrm{m} \mathrm{ATP}, 2 \mu \mathrm{Ci}$ of $\left[\gamma^{-}{ }^{32} \mathrm{P}\right] \mathrm{ATP}$ (Hartmann Analytic). The reactions were stopped by boiling in Laemmli SDSPAGE loading buffer. GST alone was tested as negative control. To monitor the amount of complexes, proteins were stained with Coomassie after separation on $10 \%$ SDS-PAGE. TLK and TLK $^{\text {dead }}$ were detected by immunoblotting with anti-TLK antibodies (data not shown). ${ }^{32} \mathrm{P}$ incorporation was revealed by autoradiography.

\section{Acknowledgments}

We thank T. Häder for initial work on $t l k$ and U. Schäfer for providing the $t$ lk P-element. We thank R. Maeda for comments on the manuscript, and D. Pauli, M. Zeidler, and R. Pflanz for discussions. We also thank J. Wuest for scanning EM, and P. Spierer for support. Special thanks to Olga Derkatch. We acknowledge E. Favre, G. Dowe, G. Faustino, and H. Taubert for technical assistance. Work was supported by grants from the Swiss National Foundation, the state of Geneva (F.K.), and the Max-Planck Society (H.).).

The publication costs of this article were defrayed in part by payment of page charges. This article must therefore be hereby marked "advertisement" in accordance with 18 USC section 1734 solely to indicate this fact.

\section{References}

Adams, M.D., Celniker, S.E., Holt, R.A., Evans, C.A., Gocayne, J.D., Amanatides, P.G., Scherer, S.E., Li, P.W., Hoskins, R.A., Galle, R.F., et al. 2000. The genome sequence of Drosophila melanogaster. Science 287: 2185-2195.

Badenhorst, P., Voas, M., Rebay, I., and Wu, C. 2002. Biological functions of the ISWI chromatin remodeling complex NURF. Genes \& Dev. 16: 3186-3198.

Bakkenist, C.J. and Kastan, M.B. 2003. DNA damage activates ATM through intermolecular autophosphorylation and dimer dissociation. Nature 421: 499-506.

Brand, A.H. and Perrimon, N. 1993. Targeted gene expression as a means of altering cell fates and generating dominant phenotypes. Development 118: 401-415.

Chou, T.B. and Perrimon, N. 1996. The autosomal FLP-DFS technique for generating germline mosaics in Drosophila melanogaster. Genetics 144: 1673-1679.

Dang, D.T. and Perrimon, N. 1992. Use of a yeast site-specific recombinase to generate embryonic mosaics in Drosophila. Dev. Genet. 13: 367-375.

Deuring, R., Fanti, L., Armstrong, J.A., Sarte, M., Papoulas, O., Prestel, M., Daubresse, G., Verardo, M., Moseley, S.L., Berloco, M., et al. 2000. The ISWI chromatin-remodeling protein is required for gene expression and the maintenance of higher order chromatin structure in vivo. Mol. Cell 5: 355365.

Emili, A., Schieltz, D.M., Yates III, J.R., and Hartwell, L.H. 2001. Dynamic interaction of DNA damage checkpoint protein Rad53 with chromatin assembly factor Asf1. Mol. Cell 7: 13-20.

Enomoto, S. and Berman, J. 1998. Chromatin assembly factor I contributes to the maintenance, but not the re-establishment, of silencing at the yeast silent mating loci. Genes \& Dev. 12: 219-232.

Foe, V.E. 1989. Mitotic domains reveal early commitment of cells in Drosophila embryos. Development 107: 1-22.

Groth, A., Lukas, J., Nigg, E.A., Silljé, H.H.W., Wernstedt, C., Bartek, J., and Hansen, K. 2003. Human Tousled like kinases are targeted by a ATM- and Chk1-dependent DNA damage checkpoint. EMBO I. 22: 1676-1687.

Gruss, C., Wu, J., Koller, T., and Sogo, J.M. 1993. Disruption of the nucleosomes at the replication fork. EMBO J. 12: 4533 4545.

Hanks, S.K., Quinn, A.M., and Hunter, T. 1988. The protein kinase family: Conserved features and deduced phylogeny of the catalytic domains. Science 241: 42-52.

Hari, K.L., Cook, K.R., and Karpen, G.H. 2001. The Drosophila $\mathrm{Su}(\mathrm{var}) 2-10$ locus regulates chromosome structure and function and encodes a member of the PIAS protein family. Genes \& Dev. 15: 1334-1348.

Hauptmann, G. and Gerster, T. 1996. Multicolor whole mount in situ hybridisation to Drosophila embryos. Genes \& Dev. Evol. 206: 292-295.

Hendzel, M.J., Wei, Y., Mancini, M.A., VanHooser, A., Ranalli, T., Brinkley, B.R., BazettJones, D.P., and Allis, C.D. 1997. Mitosis-specific phosphorylation of histone $\mathrm{H} 3$ initiates primarily within pericentromeric heterochromatin during G2 and spreads in an ordered fashion coincident with mitotic chromosome condensation. Chromosoma 106: 348-360.

Jenuwein, T. and Allis, C.D. 2001. Translating the histone code. Science 293: 1074-1080.

Le, S., Davis, C., Konopka, J.B., and Sternglanz, R. 1997. Two new S-phase-specific genes from Saccharomyces cerevisiae. Yeast 13: 1029-1042.

Li, Y., DeFatta, R., Anthony, C., Sunavala, G., and De Benedetti, A. 2001. A translationally regulated Tousled kinase phosphorylates histone $\mathrm{H} 3$ and confers radioresistance when overexpressed. Oncogene 20: 726-738.

Lucchini, R., Wellinger, R.E., and Sogo, J.M. 2001. Nucleosome positioning at the replication fork. EMBO J. 20: 7294-7302.

Luger, K., Mader, A.W., Richmond, R.K., Sargent, D.F., and Richmond, T.J. 1997. Crystal structure of the nucleosome core particle at $2.8 \AA$ resolution. Nature 389: 251-260.

Mello, J.A. and Almouzni, G. 2001. The ins and outs of nucleosome assembly. Curr. Opin. Genet. Dev. 11: 136-141.

Mello, J.A., Silljé, H.H., Roche, D.M., Kirschner, D.B., Nigg, E.A., and Almouzni, G. 2002. Human Asf1 and CAF-1 interact and synergize in a repair-coupled nucleosome assembly pathway. EMBO Rep. 3: 329-334.

Milan, M., Diaz-Benjumea, F.J., and Cohen, S.M. 1998. Beadex encodes an LMO protein that regulates Apterous LIM-homeodomain activity in Drosophila wing development: A model for LMO oncogene function. Genes \& Dev. 12: 29122920.

Moshkin, Y.M., Armstrong, J.A., Maeda, R.K., Tamkun, J.W., Verrijzer, P., Kennison, J.A., and Karch, F. 2002. Histone chaperone ASF1 cooperates with the Brahma chromatin-remodelling machinery. Genes \& Dev. 16: 2621-2626.

Nelson, D.M., Ye, X., Hall, C., Santos, H., Ma, T., Kao, G.D., Yen, T.J., Harper, J.W., and Adams, P.D. 2002. Coupling of 
Carrera et al.

DNA synthesis and histone synthesis in S phase independent of cyclin/cdk2 activity. Mol. Cell. Biol. 22: 7459-7472.

Peter, A., Schöttler, P., Werner, M., Beinert, N., Dowe, G., Burkert, P., Mourkioti, F., Dentzer, L., He, Y., Deak, P., et al.. 2002. Mapping and identification of essential gene functions on the X chromosome of Drosophila. EMBO Rep. 3: 34-38.

Platero, J.S., Hartnett, T., and Eissenberg, J.C. 1995. Functional analysis of the chromo domain of HP1. EMBO J. 14: 39773986.

Ray-Gallet, D., Quivy, J.P., Scamps, C., Martini, E.M., Lipinski, M., and Almouzni, G. 2002. HIRA is critical for a nucleosome assembly pathway independent of DNA synthesis. Mol. Cell 9: 1091-1100.

Richards, E.J. and Elgin, S.C. 2002. Epigenetic codes for heterochromatin formation and silencing: Rounding up the usual suspects. Cell 108: 489-500.

Roe, J.L., Rivin, C.J., Sessions, R.A., Feldmann, K.A., and Zambryski, P.C. 1993. The Tousled gene in A. thaliana encodes a protein kinase homolog that is required for leaf and flower development. Cell 75: 939-950.

Roe, J.L., Nemhauser, J.L., and Zambryski, P.C. 1997. TOUSLED participates in apical tissue formation during gynoecium development in Arabidopsis. Plant Cell 9: 335-353.

Sharp, J.A., Fouts, E.T., Krawitz, D.C., and Kaufman, P.D. 2001. Yeast histone deposition protein Asflp requires Hir proteins and PCNA for heterochromatic silencing. Curr. Biol. 11: 463-473.

Shibahara, K. and Stillman, B. 1999. Replication-dependent marking of DNA by PCNA facilitates CAF-1-coupled inheritance of chromatin. Cell 96: 575-585.

Silljé, H.H. and Nigg, E.A. 2001. Identification of human Asf1 chromatin assembly factors as substrates of Tousled-like kinases. Curr. Biol. 11: 1068-1073.

Silljé, H.H., Takahashi, K., Tanaka, K., Van Houwe, G., and Nigg, E.A. 1999. Mammalian homologues of the plant Tousled gene code for cell-cycle- regulated kinases with maximal activities linked to ongoing DNA replication. EMBO J. 18: 5691-5702.

Smith, S. and Stillman, B. 1991. Stepwise assembly of chromatin during DNA replication in vitro. EMBO J. 10: 971-980.

Sogo, J.M., Stahl, H., Koller, T., and Knippers, R. 1986. Structure of replicating simian virus 40 minichromosomes. The replication fork, core histone segregation and terminal structures. J. Mol. Biol. 189: 189-204.

Sutton, A., Bucaria, J., Osley, M.A., and Sternglanz, R. 2001. Yeast ASF1 protein is required for cell cycle regulation of histone gene transcription. Genetics 158: 587-596.

Thompson, J.D., Higgins, D.G., and Gibson, T.J. 1994. CLUSTAL W: Improving the sensitivity of progressive multiple sequence alignment through sequence weighting, position-specific gap penalties and weight matrix choice. Nucleic Acids Res. 22: 4673-4680.

Turner, B.M., Birley, A.J., and Lavender, J. 1992. Histone H4 isoforms acetylated at specific lysine residues define individual chromosomes and chromatin domains in Drosophila polytene nuclei. Cell 69: 375-384.

Tyler, J.K. 2002. Chromatin assembly. Eur. I. Biochem. 269: 2268-2274.

Tyler, J.K., Adams, C.R., Chen, S.R., Kobayashi, R., Kamakaka, R.T., and Kadonaga, J.T. 1999. The RCAF complex mediates chromatin assembly during DNA replication and repair. $\mathrm{Na}$ ture 402: 555-560.

Tyler, J.K., Collins, K.A., Prasad-Sinha, J., Amiott, E., Bulger, M., Harte, P.J., Kobayashi, R., and Kadonaga, J.T. 2001. In- teraction between the Drosophila CAF-1 and ASF1 chromatin assembly factors. Mol. Cell. Biol. 21: 6574-6584.

Umehara, T., Chimura, T., Ichikawa, N., and Horikoshi, M. 2002. Polyanionic stretch-deleted histone chaperone cial/ Asflp is functional both in vivo and in vitro. Genes Cells 7: 59-73.

Wang, Y., Zhang, W., Jin, Y., Johansen, J., and Johansen, K.M. 2001. The JIL-1 tandem kinase mediates histone H3 phosphorylation and is required for maintenance of chromatin structure in Drosophila. Cell 105: 433-443.

Wei, Y., Yu, L.L., Bowen, J., Gorovsky, M.A., and Allis, C.D. 1999. Phosphorylation of histone H3 is required for proper chromosome condensation and segregation. Cell 97: 99-109.

Ye, X.F., Franco, A.A., Santos, H., Nelson, D.M., Kaufman, P.D., and Adams, P.D. 2003. Defective $S$ phase chromatin assembly causes DNA damage, activation of the $S$ phase checkpoint, and S phase arrest. Mol. Cell 11: 341-351.

Zhang, Z., Shibahara, K., and Stillman, B. 2000. PCNA connects DNA replication to epigenetic inheritance in yeast. Nature 408: $221-225$. 


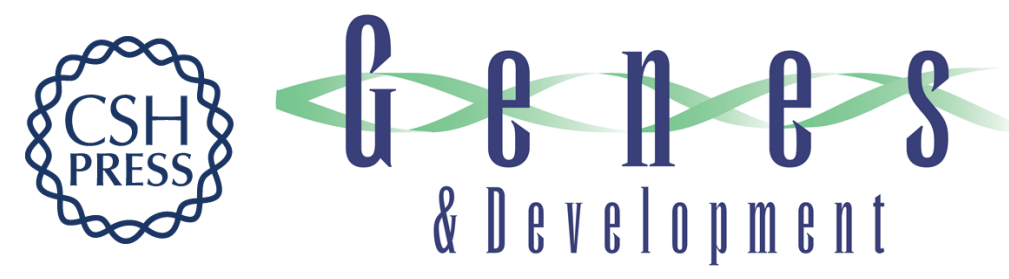

\section{Tousled-like kinase functions with the chromatin assembly pathway regulating nuclear divisions}

Pilar Carrera, Yuri M. Moshkin, Sebastian Grönke, et al.

Genes Dev. 2003, 17:

Access the most recent version at doi:10.1101/gad.276703

$\begin{array}{ll}\text { References } & \begin{array}{l}\text { This article cites } 49 \text { articles, } 17 \text { of which can be accessed free at: } \\ \text { http://genesdev.cshlp.org/content/17/20/2578.full.html\#ref-list-1 }\end{array}\end{array}$

License

Email Alerting Receive free email alerts when new articles cite this article - sign up in the box at the top Service right corner of the article or click here.

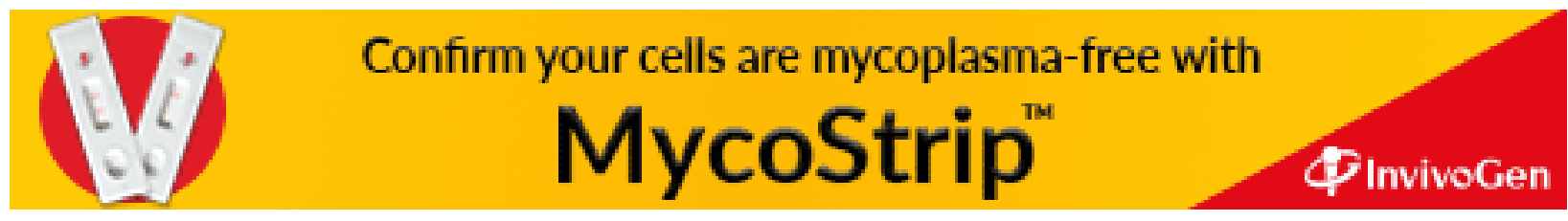

